\title{
Commentary: Necessity is the mother of invention for heart kids in the developing world
}

\author{
Nicholas D. Andersen, MD, Caroline A. McElhannon, BS, and Joseph W. Turek, MD, PhD
}

\author{
From the Duke Congenital Heart Research \& Training Laboratory, Duke University, Durham, NC. \\ Disclosures: Authors have nothing to disclose with regard to commercial support. \\ Received for publication July 22, 2019; revisions received July 22, 2019; accepted for publication July 22, 2019; \\ available ahead of print Oct 8, 2019. \\ Address for reprints: Joseph W. Turek, MD, PhD, Division of Cardiovascular and Thoracic Surgery, Duke Uni- \\ versity Medical Center, 2301 Erwin Rd, DUMC 3474, Durham, NC 27710 (E-mail: joseph.turek@ duke.edu). \\ J Thorac Cardiovasc Surg 2020;159:e241-2 \\ $0022-5223 / \$ 36.00$ \\ Copyright (C) 2019 by The American Association for Thoracic Surgery \\ https://doi.org/10.1016/j.jtcvs.2019.07.142
}

Advances in technology and understanding of congenital heart disease (CHD) have led to an era of more minimally invasive procedures. In their case report in this issue of the Journal, Pradegan and colleagues ${ }^{1}$ describe the surgical course for a patient with tricuspid atresia type 1B treated at the CEDIMAT Cardiovascular Center in Santo Domingo, capital city of the Dominican Republic. Although a bidirectional cavopulmonary connection, or Glenn anastomosis (BDG), traditionally involves a sternotomy and cardiopulmonary bypass, this report details the successful completion of the procedure through a subaxillary approach that used a venovenous shunt between the innominate vein and the right atrium, with a good clinical outcome. Other reported cases have shown promising outcomes off pump, ${ }^{2}$ and the subaxillary approach has been used for other CHD operations with muscle sparing and lesser skin stretching. . $^{3-4}$ This particular case, however, is believed to be the first reported off-pump bidirectional Glenn anastomosis through the subaxillary approach, addressing the needs of the patient while also presenting a new, socioeconomically aware approach born out of the necessity for improving surgical treatment of CHD in developing countries.

Although impressive on its own, the implications of the success of this case extend further than an alternative surgical approach. This case suggests a method that takes into consideration the available resources and facilities in developing countries and provides a practical solution for increasing access to care. The use of a surgical technique that requires less resources while still yielding successful results indicates that procedures of this kind could be feasible more often and in more facilities. The less invasive approach, without a sternotomy to monitor, could mean less time in the hospital. In addition, because follow-up can be difficult and less attainable in developing areas, a smoother postoperative recovery could be significant.

Worthy of recognition as well is the team behind this report. Dr Juan R. Leon-Wyss serves as the current head of Pediatric Cardiac Surgery at the CEDIMAT Cardiovascular Center, which has become a leading program for

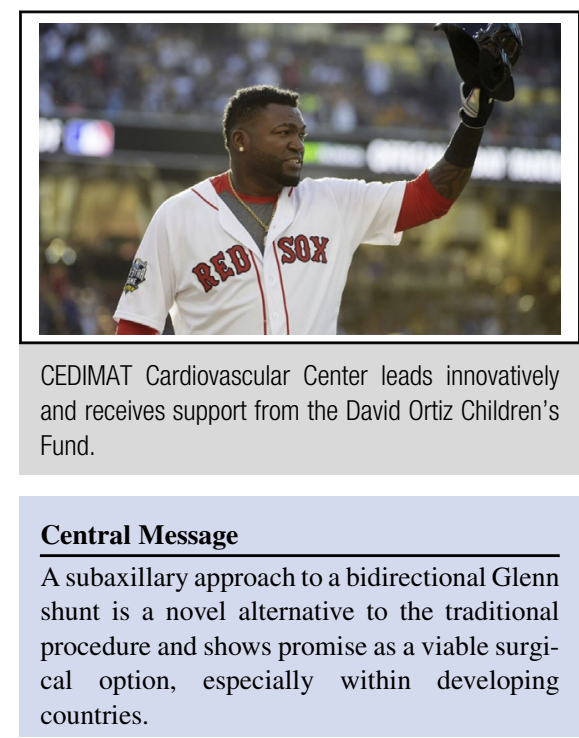

See Article page e235.

CHD care in the Caribbean and even receives support from the David Ortiz Children's Foundation. Before his time at CEDIMAT, Leon-Wyss also served as chief of Pediatric Cardiac Surgery for more than a decade at the Unidad Cardiovascular de Guatemala (UNICAR), the Guatemalan facility established by the 74th president of the American Association for Thoracic Surgery, Aldo Castañeda, in his "retirement." Although UNICAR was the first facility of its kind to treat congenital heart defects in Central America, ${ }^{5}$ establishments such as CEDIMAT in the Dominican Republic and individuals such as Leon-Wyss continue to expand the reach of medicine and increase access to care for patients living with congenital heart disease.

In summary, this case demonstrates not only a successful variation in the surgical treatment of a single functional ventricle heart defect but one that has potential to better patient care in developing countries. With lessened required resources and shortened hospital stays, less invasive operations, such as the one in this report, recognize the needs of those served in both medical and social manners. In this case, it seems the team at CEDIMAT "knows best."

\section{References}

1. Pradegan N, Mariñez Muñoz Y, Vida VL, Leon-Wyss JR. Subaxillary bidirectional cavopulmonary anastomosis in an infant. J Thorac Cardiovasc Surg. 2020;159: e235-7. 
2. Dixit M, Gan M, Dubey A, Kizakke Kuttikot P, Mohapatra R, Dayal A. Off pump bidirectional Glenn performed through a thoracotomy. Ind J Thorac Cardiovasc Surg. 2007;23:180-3.

3. Vida VL, Zanotto L, Zanotto L, Tessari C, Padalino MA, Zanella F, et al. Minimally invasive surgery for atrial septal defects: a 20-year experience at a single centre. Interact Cardiovasc Thorac Surg. 2019;28:961-7.
4. Dodge-Khatami A, Salazar JD. Right axillary thoracotomy for transatrial repair of congenital heart defects: VSD, partial AV canal with mitral cleft, PAPVR or Warden, cor triatriatum and ASD. Oper Tech Thorac Cardiovasc Surg. 2016;20:384-401.

5. Del Nido P. Aldo R. Castañeda, MD, PhD: recipient of the Lifetime Achievement Award and 74th president of The American Association for Thoracic Surgery. J Thorac Cardiovasc Surg. 2018;155:847-9. 